\title{
Microgram per Fifteen Milliliters
}

National Cancer Institute

\section{Source}

National Cancer Institute. Microgram per Fifteen Milliliters. NCI Thesaurus. Code C91132.

The quantity of micrograms in a volume of fifteen milliliters of a substance. 